\title{
Metodologias de aplicação de AIB no enraizamento de estacas semilenhosas de Sapium glandulatum (Vell.) Pax
}

\author{
FERREIRA, B.G.A. ${ }^{1}$; ZUFFELLATO-RIBAS, K.C. ${ }^{2^{*}}$; CARPANEZZI, A.A. ${ }^{3}$; TAVARES, F.R. ${ }^{3}$; KOEHLER, H.S. ${ }^{4}$ \\ ${ }^{1}$ Departamento de Fitotecnia e Fitossanitarismo, Universidade Federal do Paraná, Rua dos Funcionários, 1540. \\ 81531-970-Curitiba/PR alpande@terra.com.br. ${ }^{2}$ Departamento de Botânica, Universidade Federal do Paraná, \\ Centro Politécnico - Jardim das Américas. 81531-970-Curitiba/PR *kazu@ufpr.br. ${ }^{3}$ Embrapa Florestas, Estrada \\ da Ribeira, Km 111. 83411-000-Colombo/PR carpa@cnpf.embrapa.br. ${ }^{4}$ Departamento de Fitotecnia e \\ Fitossanaitarismo, Universidade Federal do Paraná, Rua dos Funcionários, 1540. 80035-050-Curitiba/PR \\ koehler@ufpr.br.
}

\begin{abstract}
RESUMO: A espécie Sapium glandulatum, conhecida vulgarmente como leiteiro, é uma das espécies nativas potencialmente recomendada para a recuperação de áreas degradadas, devido principalmente ao seu caráter pioneiro, além de possivelmente possuir características medicinais, uma vez que a família Euphorbiaceae, a qual pertence, é rica em compostos fenólicos. Em abril/ 2000 e dezembro/2000 foram conduzidos experimentos em casa-de-vegetação para verificar o efeito da aplicação de diferentes concentrações de ácido indolilbutírico (AIB), em solução concentrada (10 segundos de imersão), solução diluída (16 horas de imersão) e em talco, associadas ou não ao ácido bórico, no enraizamento de estacas semilenhosas de Sapium glandulatum. As estacas foram confeccionadas a partir de brotações do ano, coletadas de plantas matrizes localizadas no município de Bocaiúva do Sul -PR, mantendo- as com comprimento de cerca de $10 \mathrm{~cm}$ e 2 folhas apicais reduzidas à metade. Os tratamentos utilizados foram: 0, 4000, 6000 e $8000 \mathrm{mg} \mathrm{L}^{-1}$ de AIB, sozinhos e em associação com $150 \mathrm{mg} \mathrm{L}^{-1}$ de ácido bórico (solução concentrada), 0, 200 e $400 \mathrm{mg} \mathrm{L}^{-1}$ de AlB, sozinhos e em associação com $150 \mathrm{mg} \mathrm{L}^{-1}$ ácido bórico (solução diluída) e 0, 4000, 6000 e $8000 \mathrm{mg} \mathrm{L}^{-1} \mathrm{de} \mathrm{AIB}$, na forma de talco. Pelos resultados obtidos foi possível concluir que, após 70 dias em casa-de-vegetação, a melhor época para coleta das estacas correspondeu à instalação realizada em dezembro/2000 (verão), onde o tratamento com $8000 \mathrm{mg} \mathrm{L}^{-1}$ de AIB, em solução concentrada, proporcionou o maior percentual de enraizamento (14\%), porém não diferindo significativamente dos demais tratamentos. A utilização da solução diluída não se mostrou promissora para a indução do sistema radicial devido à alta mortalidade das estacas. Os tratamentos com AIB veiculados em talco não superaram os resultados obtidos pelos melhores tratamentos para estacas enraizadas em solução concentrada, não sendo um método recomendável para o aumento da indução radicial de Sapium glandulatum. Pelo exposto, pode-se considerar que estacas de brotações do ano desta espécie não são indicadas para sua propagação vegetativa, de acordo com os tratamentos realizados.
\end{abstract}

Palavras-chave: estaquia, ácido indolilbutírico, ácido bórico, plantas medicinais

ABSTRACT: Methodologies of IBA application in the rooting of Sapium glandulatum (Vell.) Pax semi-hardwood cuttings. The species Sapium glandulatum, commonly known as "leiteiro", is one of the Brazilian native species potentially recommended for the recovery of degraded areas, mainly due to its pioneering character and probable medicinal properties since its family, Euphorbiaceae, is rich in phenolic compounds. In April/2000 and December/2001, experiments were carried out in a greenhouse to investigate the effects of different indolebutyric acid (IBA) levels in concentrated solution (10 seconds immersion), diluted solution (16 hours immersion) and as talc, associated or not with boric acid, on the rooting of Sapium glandulatum semi-hardwood cuttings. The latter were produced from sproutings of the year collected from stock plants located in Bocaiúva do Sul, Paraná State, Brazil. The length of each cutting was about $10 \mathrm{~cm}$, with 2 half apical leaves. The following treatments were evaluated: 0, 4000, 6000 and $8000 \mathrm{mg} \mathrm{L}^{-1}$ IBA, alone and with $150 \mathrm{mg} \mathrm{L}^{-1}$ boric acid (concentrated solution); 0, 200 and $400 \mathrm{mg} \mathrm{L}^{-1}$ IBA, alone and with $150 \mathrm{mg} \mathrm{L}^{-1}$ boric acid (diluted solution); and 0, 4000, 6000 and $8000 \mathrm{mg} \mathrm{L}^{-1}$ IBA as talc. After 70

Recebido para publicação em 26/05/2008

Aceito para publicação em 31/10/2008

Rev. Bras. PI. Med., Botucatu, v.11, n.2, p.196-201, 2009. 
days in greenhouse, the best period for cutting collection was December/2000 (summer), and $8000 \mathrm{mg} \mathrm{L}^{-1}$ IBA in concentrated solution led to the highest rooting percentage (14\%), although not significantly different from the remaining treatments. The diluted solution did not show promising results for root system induction due to the high mortality of cuttings. The results for IBA as talc were not higher than those for the best treatments in concentrated solution, which indicates this method is not recommended to increase Sapium glandulatum rooting induction. Thus, sprouting cuttings of the year from this species are not recommended for its vegetative propagation, according to the evaluated treatments.

Key words: cutting, indolebutyric acid, boric acid, medicinal plants

\section{INTRODUÇÃO}

Sapium glandulatum, conhecida vulgarmente como leiteiro ou pau-de-leite é uma das espécies nativas potencialmente recomendada para recuperação de áreas degradadas, devido principalmente ao seu caráter pioneiro que propicia uma cobertura inicial do solo, facilitando a entrada de outras espécies (Sanchotene, 1985; Lorenzi, 1992). Porém, essa espécie possui dificuldade de regeneração por meios naturais devido à baixa porcentagem de germinação de suas sementes (Sanchotene, 1985; Lorenzi, 1992). A espécie também possui características medicinais, uma vez que a família Euphorbiaceae, a qual pertence, é rica em compostos fenólicos, especialmente taninos, os quais são usados como medicamentos psicotrópicos e anticancerígenos.

A utilização de mudas de espécies nativas apresenta importância sob vários aspectos econômicos e sociais. Os sistemas agroflorestais representam alternativas viáveis para a recuperação de áreas degradadas em pequenas propriedades e para a fixação do pequeno produtor no campo (Reis \& Hildebrand, 2000), assim como para o enriquecimento de reservas florestais (Xavier \& Santos, 2002).

Entretanto, com a crescente demanda do mercado para plantio em áreas degradadas, a escassez de mudas de espécies nativas dificulta a implantação de projetos de revegetação (Xavier \& Santos, 2002). A escassa quantidade de mudas disponíveis no mercado é suprida por iniciativas pontuais de instituições públicas e privadas que desenvolvem projetos de manejo visando à silvicultura para espécies de interesse particular para produção de mudas e estudos sobre plantio, espaçamento, sistemas de condução do fuste, nutrição, além de características da reprodução sexuada e assexuada (Rocha, 2002).

Basicamente, para a recuperação de áreas degradadas são utilizadas mudas provenientes de sementes, devido à maior facilidade de obtenção das mesmas. No entanto, em algumas espécies florestais nativas, se faz necessária a utilização da propagação vegetativa devido à baixa produção de sementes ou pela dificuldade de germinação das mesmas (Sanchotene, 1985).

Portanto, para a recuperação dessas áreas com espécies de difícil regeneração por meios naturais, é de suma importância o desenvolvimento de técnicas que favoreçam a propagação vegetativa dessas espécies (Silva, 1984).

O estudo da propagação vegetativa da espécie se faz necessário, podendo ser utilizado como uma alternativa à produção de mudas ou podendo substituir a propagação via semente, uma vez que Sanchotene (1985) e Lorenzi (1992) relatam que a espécie Sapium glandulatum possui produção e taxa de germinação das sementes extremamente baixa e, quando em ambiente adverso, perdem rapidamente a viabilidade. Segundo os mesmos autores, um dos métodos mais empregados para a propagação vegetativa da referida espécie é por meio de estacas.

Em linhas gerais, a propagação vegetativa é a multiplicação de um vegetal a partir de tecidos que possuem capacidade de reassumir suas atividades meristemáticas. É a maneira mais rápida e segura de se obter uma nova planta com características iguais a do vegetal que a originou (Silva, 1984).

Porém, a obtenção de plantas por estaquia é um processo lento e impraticável para algumas espécies que não possuem a composição química endógena necessária. Esse entrave pode ser resolvido com o emprego de alguns reguladores vegetais, especificamente do grupo das auxinas e de co-fatores do enraizamento, que além de estimularem e acelerarem o enraizamento das estacas, uniformizam e induzem a formação de raízes em plantas tidas como de difícil enraizamento (Ono et al., 1994; Zanette, 1995).

Os co-fatores do enraizamento são considerados substâncias endógenas, capazes de atuar sinergisticamente com o IAA no enraizamento de estacas. Esses co-fatores podem ser compostos fenólicos, compostos do triazol, carboidratos, boro entre outros (Hartmann et al., 2002).

Existem muitos métodos para aplicar quantidades suficientes de reguladores vegetais em 
estacas caulinares. Weaver (1982) descreve alguns destes métodos. No método de imersão rápida, a estaca permanece por aproximadamente 5 segundos, em solução alcoólica de auxina concentrada (500 a $10000 \mathrm{mg} \mathrm{L}^{-1}$ ). Concentrações muito elevadas podem inibir o desenvolvimento de gemas ou provocar o amarelecimento e queda das folhas, provocando a morte da estaca. No método de imersão prolongada, as concentrações variam de $20 \mathrm{mg} \mathrm{L}^{-1}$, para espécies de fácil enraizamento, até $200 \mathrm{mg} \mathrm{L}^{-1}$, para espécies de difícil enraizamento, sendo as estacas mantidas na solução por cerca de 24 horas.

Sendo assim, o presente trabalho teve como objetivo verificar o enraizamento de estacas semilenhosas de Sapium glandulatum, a partir da coleta de brotações do ano de plantas matrizes adultas, utilizando diferentes concentrações de ácido indolilbutírico, em diferentes métodos de aplicação.

\section{MATERIAL E MÉTODO}

O presente experimento foi conduzido em casa-de-vegetação da Embrapa Florestas, no Município de Colombo - PR. As estacas foram coletadas no Sítio Mocelim, localizado na região de Tarimba, no município de Bocaiúva do Sul - PR, situado à $49^{\circ} 06^{\prime} 54^{\prime \prime}$ de longitude ocidental e 25 $12^{\prime}$ 22" de latitude sul, a uma altitude de cerca de 980 metros, em duas épocas do ano: outono - abril/2000 e verão - dezembro/2000. O material vegetal foi obtido a partir de brotações do ano de plantas matrizes adultas de Sapium glandulatum, cuja excicata foi registrada no herbário do Curso de Engenharia Florestal, da Universidade Federal do Paraná, com o número CFC 9204.

O comprimento estabelecido para as estacas foi de $10 \mathrm{~cm}$, contendo um par de folhas na porção apical, reduzidas à metade. Para a desinfestação do material vegetal, as estacas foram tratadas com solução de hipoclorito de sódio a $0,5 \%$ (ação bactericida) e Benlate a $0,5 \mathrm{~g} \mathrm{~L}^{-1}$ (ação fungicida). Posteriormente, as estacas de Sapium glandulatum foram submetidas a tratamentos com ácido indolilbutírico (AIB) e ácido bórico na forma de solução, por um período de 10 segundos de imersão (solução concentrada) e um período de 16 horas (solução diluída), além dos tratamentos veiculados em talco, descritos a seguir: 0, 4000, 6000 e $8000 \mathrm{mg} \mathrm{L}^{-1}$ de AIB, sozinhos e em associação com $150 \mathrm{mg} \mathrm{L}^{-1} \mathrm{de}$ ácido bórico (solução concentrada), 0, 200 e $400 \mathrm{mg}$ $\mathrm{L}^{-1}$ de AIB, sozinhos e em associação com $150 \mathrm{mg} \mathrm{L}^{-1}$ de ácido bórico (solução diluída) e 0, 4000, 6000 e $8000 \mathrm{mg} \mathrm{L}^{-1}$ de AIB, na forma de talco.

Uma vez plantadas em bandejas de enraizamento com vermiculita de granulometria média como substrato, as estacas foram mantidas em casade-vegetação com sistema de nebulização com intervalos de 5 minutos, onde a cada intervalo a irrigação permanecia ligada por 5 segundos. As estacas permaneceram em casa-de-vegetação por um período de 70 dias, quando então foram avaliadas as seguintes características:

-porcentagem de enraizamento (estacas vivas que apresentaram raízes de, no mínimo $1 \mathrm{~mm}$ de comprimento, podendo ou não apresentar calos); -porcentagem de estacas com calos (estacas vivas, sem raízes, com formação de massa celular indiferenciada na base);

- porcentagem de sobrevivência (estacas vivas que não apresentaram indução radicial nem formação de calos);

-porcentagem de mortalidade (estacas que se encontravam com tecidos necrosados).

O delineamento experimental utilizado foi inteiramente casualizado, com 17 tratamentos, 5 repetições e 10 estacas por parcela, analisado em cada época separadamente. Os resultados foram submetidos à análise de variância, onde os tratamentos foram analisados pelo teste "Bartlett" quanto à sua homogeneidade. As características cujas variâncias mostraram-se homogêneas tiveram as médias dos tratamentos testadas pelo teste $\mathrm{F}$, enquanto as que apresentaram heterogeneidade ou tratavam-se de contagem, tiveram seus valores originais transformados em $(X+10)^{1 / 2}$ e, posterior, análise dos dados transformados. Quando os resultados revelaram existir diferenças significativas entre as médias dos tratamentos, as médias foram comparadas pelo teste Tukey ao nível de $5 \%$ de probabilidade.

\section{RESULTADOE DISCUSSÃO}

As coletas de brotações do ano de Sapium glandulatum foram realizadas nas quatro estações do ano, a fim de se determinar a melhor época de coleta do material vegetal. No entanto, são apresentados no presente trabalho somente resultados referentes ao outono/2000 e verão/2000, uma vez que no inverno/2000, as estacas apresentaram $100 \%$ de mortalidade, em todos os tratamentos, fato que inviabilizou a apresentação dos mesmos. Nesta estação ocorreram fortes geadas na área de coleta, as quais comprometeram a qualidade do material coletado, acarretando na mortalidade precoce das estacas. Ainda em conseqüência destas geadas, na primavera $/ 2000$, os brotos recémformados das plantas matrizes eram extremamente tenros e inviáveis para a estaquia, não sendo possível apresentar esses dados.

Assim, os resultados para as coletas realizadas no outono/2000 e verão/2000 apresentaram heterogeneidade da variância dos tratamentos, para todas as características e estações estudadas, 
quando realizado o teste Bartlett, tendo seus valores originais transformados $\left[(X+10)^{1 / 2}\right]$, para posterior análise dos dados transformados.

\section{-Outono (Abril/2000)}

A análise estatística foi realizada somente para as características porcentagem de sobrevivência e mortalidade. As demais características apresentaram grande quantidade de valores nulos, não sendo estatisticamente analisados. A Tabela 1 apresenta somente as médias para as características em que não foi realizada a análise estatística e a comparação de médias para as variáveis que puderam ser analisadas estatisticamente.

O outono apresentou baixa porcentagem de enraizamento, sendo as maiores porcentagens obtidas nas concentrações de $4000 \mathrm{mg} \mathrm{L}^{-1}$ de IBA e $6000 \mathrm{mg} \mathrm{L}^{-1} \mathrm{de} A \mathrm{IB}+150 \mathrm{mg} \mathrm{L}^{-1}$ de ácido bórico em solução concentrada e 0 e $4000 \mathrm{mg} \mathrm{L}^{-1}$ de AIB em talco, todos com $4 \%$ de enraizamento. A adição de ácido bórico não otimizou o enraizamento de Sapium glandulatum.

Ferreira et al. (2001), em experimentos realizados com a mesma espécie utilizando soluções concentradas de AIB e adicionando a mesma concentração de ácido bórico (150 $\left.\mathrm{mg} \mathrm{L}^{-1}\right)$, observaram que o ácido bórico associado ao AIB não aumentou a porcentagem de enraizamento, concordando assim com os resultados obtidos no presente trabalho.

Os tratamentos com soluções diluídas não demonstraram efeito no enraizamento de estacas $(0 \%$ de enraizamento), independente da concentração de IBA, apresentando alta taxa de mortalidade, sendo a maior porcentagem observada nas concentrações de $200 \mathrm{mg} \mathrm{L}^{-1}$ de AlB e $200 \mathrm{mg} \mathrm{L}^{-1}$ de AIB $+150 \mathrm{mg} \mathrm{L}^{-1}$ de ácido bórico (98\%) não diferindo estatisticamente dos demais tratamentos (Tabela 1). Para a porcentagem de estacas vivas, os tratamentos não diferiram significativamente, sendo as menores porcentagens encontradas nos tratamentos com soluções diluídas (Tabela 1).

Esses resultados para soluções diluídas podem ter ocorrido por uma característica da espécie, que necessita de soluções concentradas, ou seja, concentrações mais altas de AIB para estabelecer um sistema radicial. Os dados vão ao encontro dos resultados obtidos por Castro et al. (1984) os quais, trabalhando com seringueira, relataram que parte das estacas que receberam o ácido indolilbutírico diluído em $\mathrm{KOH}$, em tratamentos de imersão basal por 12 horas, sofreram efeito prejudicial por esse tratamento, manifestado por necrose dos tecidos da base, inibindo a produção de raízes. A mesma espécie, estudada por Castro et al. (1987), teve as estacas tratadas com IBA na concentração de $2500 \mathrm{mg} \mathrm{L}^{-1}$ por período de imersão de 1 hora, apresentando baixa porcentagem de enraizamento $(7,7 \%)$. Com isso, pode-se inferir que Sapium glandulatum necessita de períodos curtos de imersão nos reguladores vegetais, como a Hevea brasiliensis (seringueira), devido às duas espécies

TABELA 1. Comparação de médias da porcentagem de estacas de Sapium glandulatum enraizadas (E.E.), com calos (E.C.), vivas (E.V.) e mortas (E.M.), no experimento instalado no outono (abril/2000).

\begin{tabular}{|c|c|c|c|c|c|}
\hline & $\begin{array}{c}\text { Tratamentos } \\
\left(\mathrm{mg} \mathrm{L}^{-1} \text { ou } \mathrm{mg} \mathrm{Kg}^{-1}\right)\end{array}$ & E.E. (\%) & E.C. $(\%)$ & E.V. (\%) & E.M. (\%) \\
\hline \multirow{8}{*}{$\begin{array}{c}\text { Solução } \\
\text { concentrada }\end{array}$} & $0 \mathrm{AlB}$ & 2,0 & 20,0 & $24,0 \mathrm{~A}$ & $54,0 \quad C$ \\
\hline & 4000 AlB & 4,0 & 12,0 & $10,0 \mathrm{~A}$ & $64,0 \quad B C$ \\
\hline & $6000 \mathrm{AlB}$ & 0,0 & 8,0 & $14,0 \mathrm{~A}$ & $78,0 \mathrm{ABC}$ \\
\hline & $8000 \mathrm{AlB}$ & 0,0 & 0,0 & $16,0 \mathrm{~A}$ & $84,0 \mathrm{ABC}$ \\
\hline & 150 ácido bórico & 0,0 & 14,0 & $12,0 \mathrm{~A}$ & $74,0 \mathrm{ABC}$ \\
\hline & 4000 AlB + 150 ácido bórico & 0,0 & 4,0 & $14,0 \mathrm{~A}$ & $82,0 \mathrm{ABC}$ \\
\hline & 6000 AIB + 150 ácido bórico & 4,0 & 2,0 & $16,0 \mathrm{~A}$ & $78,0 \mathrm{ABC}$ \\
\hline & 8000 AlB + 150 ácido bórico & 2,0 & 8,0 & $12,0 \mathrm{~A}$ & $78,0 \mathrm{ABC}$ \\
\hline \multirow{5}{*}{ Solução diluída } & 200 AIB & 0,0 & 0,0 & $2,0 \mathrm{~A}$ & $98,0 \mathrm{~A}$ \\
\hline & $400 \mathrm{AIB}$ & 0,0 & 0,0 & $8,0 \mathrm{~A}$ & $92,0 \mathrm{AB}$ \\
\hline & 150 ácido bórico & 0,0 & 0,0 & $16,0 \mathrm{~A}$ & $84,0 \mathrm{ABC}$ \\
\hline & 200 + 150 ácido bórico & 0,0 & 0,0 & $2,0 \mathrm{~A}$ & $98,0 \mathrm{~A}$ \\
\hline & $400+150$ ácido bórico & 0,0 & 0,0 & $6,0 \mathrm{~A}$ & $94,0 \mathrm{AB}$ \\
\hline \multirow{4}{*}{ Talco } & $0 \mathrm{AlB}$ & 4,0 & 6,0 & $8,0 \mathrm{~A}$ & $82,0 \mathrm{ABC}$ \\
\hline & $4000 \mathrm{AlB}$ & 4,0 & 4,0 & $22,0 \mathrm{~A}$ & $70,0 \mathrm{ABC}$ \\
\hline & 6000 AlB & 0,0 & 6,0 & $16,0 \mathrm{~A}$ & $78,0 \mathrm{ABC}$ \\
\hline & 8000 AlB & 0,0 & 0,0 & $12,0 \mathrm{~A}$ & $88,0 \mathrm{AB}$ \\
\hline $\mathrm{CV}(\%)$ & & - & - & 94,16 & 17,55 \\
\hline
\end{tabular}

Médias seguidas da mesma letra, maiúscula nas colunas, não diferem estatisticamente pelo teste Tukey ao nível de $5 \%$ de probabilidade.

Rev. Bras. PI. Med., Botucatu, v.11, n.2, p.196-201, 2009. 
pertencerem à mesma família botânica .

No outono (abril/2000), o método com solução concentrada apresentou os maiores resultados para estacas com calos, onde o tratamento controle apresentou $20 \%$ de estacas com calos. Segundo Hartmann et al. (2002), quando as estacas são colocadas em condições de enraizamento, comumente ocorre a formação de calos, os quais são massas irregulares de células parenquimáticas em diferentes estágios de lignificação, através dos quais as raízes emergem. Porém, a formação das raízes adventícias e dos calos é independente e sua ocorrência simultânea se explica pelo fato de ambos envolverem processo de divisão celular, o que pode depender de condições internas e ambientais similares. Assim, pode-se inferir que um maior tempo das estacas no leito de enraizamento nessa época, poderia aumentar a porcentagem de enraizamento por meio da diferenciação das células do calo em primórdios radiciais.

\section{-Verão (Dezembro/2000)}

O verão foi a época de coleta que melhor favoreceu o enraizamento de estacas de Sapium glandulatum, porém não houve diferença significativa entre os tratamentos (Tabela 2). As maiores porcentagens de indução radicial foram observadas nos tratamentos com AIB $8000 \mathrm{mg} \mathrm{L}^{-1}$ AIB (14\%) e IBA $8000 \mathrm{mg} \mathrm{L}^{-1} \mathrm{AIB}$ + ácido bórico $150 \mathrm{mg} \mathrm{L}^{-1}$ ácido bórico (12\%). A associação de IBA com ácido bórico, nessa época, também não aumentou a porcentagem de enraizamento, sendo que os tratamentos não apresentaram diferenças significativas.

Ferreira et al. (2001), trabalhando com Sapium glandulatum também obtiveram os melhores resultados no verão, onde relatam que o melhor resultado nesta estação pode ser atribuído ao fato de que, no verão, os ramos apresentavam-se em pleno crescimento vegetativo, com grande emissão de gemas e folhas jovens, importantes fontes de auxina endógena.

Os mesmos autores encontraram $28 \%$ de enraizamento com o tratamento com $4000 \mathrm{mg} \mathrm{L}^{-1} \mathrm{de}$ AIB, também na estação no verão. No presente experimento, o tratamento com a mesma concentração apresentou somente $2 \%$ de enraizamento. Essa diferença de porcentagem de enraizamento pode ter ocorrido devido às diferenças climáticas desta estação, pois a média das temperaturas no período do verão, no ano de 1999, quando foi realizado o experimento por Ferreira et al. (2001), foi de $25,3^{\circ} \mathrm{C}$, enquanto a média das temperaturas no mesmo período, no presente experimento, foi de $21^{\circ} \mathrm{C}$. Essa diferença de temperatura média pode ter influenciado no desenvolvimento das plantas matrizes, pois devido a temperatura ser menor, o pleno crescimento vegetativo pode ter sido retardado, acarretando em menor emissão de gemas e folhas jovens, importantes fontes de auxina endógena, o que pode ter comprometido o enraizamento das estacas.

Os tratamentos com soluções diluídas não

TABELA2. Comparação de médias da porcentagem de estacas tratadas com AIB de Sapium glandulatum enraizadas (E.E.), com calos (E.C.), vivas (E.V.) e mortas (E.M.), no experimento instalado no verão (dezembro/2000).

\begin{tabular}{|c|c|c|c|c|c|}
\hline \multirow{9}{*}{$\begin{array}{c}\text { Solução } \\
\text { concentrada }\end{array}$} & $\begin{array}{c}\text { Tratamentos } \\
\left(\mathrm{mq} \mathrm{L}^{-1} \text { ou } \mathrm{ma} \mathrm{Kq}^{-1}\right)\end{array}$ & E.E.(\%) & E.C. (\%) & E.V.(\%) & E.M. (\%) \\
\hline & $0 \mathrm{AIB}$ & $2,0 \mathrm{~A}$ & $2,0 \mathrm{AB}$ & $8,0 \mathrm{~A}$ & $88,0 \mathrm{~A}$ \\
\hline & $4000 \mathrm{AlB}$ & $2,0 \mathrm{~A}$ & $0,0 \mathrm{~B}$ & $4,0 \mathrm{~A}$ & $94,0 \mathrm{~A}$ \\
\hline & $6000 \mathrm{AlB}$ & $8,0 \mathrm{~A}$ & $0,0 \mathrm{~B}$ & $2,0 \mathrm{~A}$ & $90,0 \mathrm{~A}$ \\
\hline & $8000 \mathrm{AlB}$ & $14,0 \mathrm{~A}$ & $0,0 \mathrm{~B}$ & $0,0 \mathrm{~A}$ & $86,0 \mathrm{~A}$ \\
\hline & 150 ácido bórico & $4,0 \mathrm{~A}$ & $0,0 \mathrm{~B}$ & $4,0 \mathrm{~A}$ & $92,0 \mathrm{~A}$ \\
\hline & 4000 AlB + 150 ácido bórico & $4,0 \mathrm{~A}$ & $0,0 \mathrm{~B}$ & $0,0 \mathrm{~A}$ & $96,0 \mathrm{~A}$ \\
\hline & 6000 AIB + 150 ácido bórico & $4,0 \mathrm{~A}$ & $0,0 \quad B$ & $0,0 \mathrm{~A}$ & $96,0 \mathrm{~A}$ \\
\hline & 8000 AlB + 150 ácido bórico & $12,0 \mathrm{~A}$ & $0,0 \quad B$ & $0,0 \mathrm{~A}$ & $88,0 \mathrm{~A}$ \\
\hline \multirow{5}{*}{$\begin{array}{l}\text { Solução } \\
\text { diluída }\end{array}$} & $200 \mathrm{AlB}$ & $0,0 \mathrm{~A}$ & $0,0 \mathrm{~B}$ & $0,0 \mathrm{~A}$ & $100,0 \mathrm{~A}$ \\
\hline & $400 \mathrm{AlB}$ & $0,0 \mathrm{~A}$ & $0,0 \quad B$ & $0,0 \mathrm{~A}$ & $100,0 \mathrm{~A}$ \\
\hline & 150 ácido bórico & $0,0 \mathrm{~A}$ & $6,0 \mathrm{~A}$ & $2,0 \mathrm{~A}$ & $92,0 \mathrm{~A}$ \\
\hline & $200+150$ ácido bórico & $0,0 \mathrm{~A}$ & $0,0 \quad B$ & $0,0 \mathrm{~A}$ & $100,0 \mathrm{~A}$ \\
\hline & 400+ 150 ácido bórico & $0,0 \mathrm{~A}$ & $0,0 \mathrm{~B}$ & $0,0 \mathrm{~A}$ & $100,0 \mathrm{~A}$ \\
\hline \multirow{4}{*}{ Talco } & $0 \mathrm{AIB}$ & $4,0 \mathrm{~A}$ & $0,0 \quad B$ & $4,0 \mathrm{~A}$ & $92,0 \mathrm{~A}$ \\
\hline & $4000 \mathrm{AlB}$ & $4,0 \mathrm{~A}$ & $0,0 \quad B$ & $4,0 \mathrm{~A}$ & $92,0 \mathrm{~A}$ \\
\hline & $6000 \mathrm{AlB}$ & $4,0 \mathrm{~A}$ & $0,0 \quad B$ & $2,0 \mathrm{~A}$ & $94,0 \mathrm{~A}$ \\
\hline & $8000 \mathrm{AlB}$ & $4,0 \mathrm{~A}$ & $0,0 \quad B$ & $4,0 \mathrm{~A}$ & $92,0 \mathrm{~A}$ \\
\hline CV (\%) & & 178,89 & 515,39 & 236,39 & 9,12 \\
\hline
\end{tabular}

Médias seguidas da mesma letra, maiúscula nas colunas, não diferem estatisticamente pelo teste Tukey ao nível de $5 \%$ de probabilidade. 
apresentaram efeito no enraizamento, apresentando $0 \%$ de enraizamento, uma alta taxa de mortalidade e baixa sobrevivência, não havendo diferenças significativas entre os tratamentos para as porcentagens de estacas vivas e mortas. No experimento de verão/2000 ocorrem altas taxas de mortalidade, chegando a $100 \%$ de estacas mortas em alguns tratamentos com soluções diluídas.

Pimenta et al. (2005), trabalhando com estacas de Sapium glandulatum, também constataram uma alta mortalidade em seus experimentos, relatando que esta pode estar relacionada à manutenção das estacas na casa-devegetação durante o período de enraizamento.

Os tratamentos veiculados em talco não apresentaram diferença entre as concentrações de IBA utilizadas, para a variável porcentagem de enraizamento, uma vez que todos os tratamentos apresentaram $4 \%$ de estacas enraizadas. Como nos demais tratamentos, a mortalidade nesse método foi elevada. Ferreira et al. (2001), utilizando tratamentos com solução concentrada e em talco em estacas semilenhosas de Sapium glandulatum, relatam que em talco apresentaram resultados inferiores aos melhores tratamentos em solução, confirmando os resultados obtidos no presente experimento, onde em talco também não superaram os maiores resultados dos tratamentos em solução concentrada.

Este método de aplicação possui a desvantagem de não produzir resultados homogêneos, devido à desuniformidade do material aderido à base das estacas. Logo, o enraizamento pode ser prejudicado, resultando assim em porcentagens baixas de estacas enraizadas.

\section{CONCLUSÃO}

Nas condições em que o presente experimento foi realizado, foi possível concluir que, no processo de enraizamento de estacas caulinares de Sapium glandulatum:

- A época de coleta dos ramos e as concentrações de AIB utilizadas influenciam no processo de enraizamento de Sapium glandulatum.

- O verão foi a melhor época de coleta dos ramos, proporcionando melhor enraizamento.

- O tratamento das estacas com IBA a 8000 mg L-1, na forma de solução concentrada, no verão, foi o mais efetivo em promover o enraizamento das estacas (14\%).

- A utilização do método de concentração diluída de IBA não se mostrou promissora para a indução do sistema radicial em Sapium glandulatum.

- Os tratamentos veiculados em talco não superaram os resultados obtidos pelos melhores tratamentos de solução concentrada de IBA para estacas enraizadas.
- Os baixos índices de enraizamento evidenciam a necessidade de maiores estudos, a fim de refinar a técnica e aumentar a porcentagem de estacas enraizadas, viabilizando deste modo, a utilização prática da propagação vegetativa dessa espécie.

\section{REFERÊNCIA}

CASTRO, P.R.C. et al. Estimulação do enraizamento da estacas de seringueira (Hevea brasiliensis Muell. Arg.). Anais da Escola Superior de Agricultura "Luiz de Queiroz", v.41, n.1, p.349-57, 1984.

CASTRO, P.R.C. et al. Estimulação do enraizamento de estacas de seringueira (Hevea brasiliensis Muell. Arg) pela aplicação de reguladores vegetais. Anais da Escola Superior de Agricultura “Luiz de Queiroz", v.64, n.2, p.1025-35, 1987.

FERREIRA, B.G.A. et al. Enraizamento de Sapium glandulatum (vell.) pax. pela aplicação de ácido indol butírico e ácido bórico. Leandra, n.16, p.11-6, 2001.

HARTMANN, H.T. et al. Plant propagation: principles and practices. 7.ed. New York: Englewood Clipps, 2002. 880p.

LORENZI, H. Árvores brasileiras: manual de identificação e cultivo de plantas arbóreas nativas do Brasil. Nova Odessa: Plantarum, 1992. 352p.

ONO, E.O.A.; RODRIGES, J.D.; PINHO, S.Z. Ação de auxinas e/ou boro, no processo de formação de raízes em estacas de café (Coffea arabica L. CV. "Mundo Novo"). Arquivos de Biologia e Tecnologia, v.37, n.1, p.157-66, 1994. PIMENTA, A.C. et al. Interações entre reguladores vegetais, épocas do ano e tipos de substrato no enraizamento de estacas caulinares de Sapium glandulatum (Vell.) Pax. (pau-de-leite). Boletim de Pesquisa Florestal, n.50, p. 53-67, 2005.

REIS, C.S.; HILDEBRAND, M.Z. Avaliação de um sistema agroflorestal com espécies arbóreas nativas visando à recuperação de áreas degradadas em pequenas propriedades rurais. In: SIMPÓSIO NACIONAL DE RECUPERAÇÃO DE ÁREAS DEGRADADAS, 6., 2000. Anais ... Blumenau, 2000. p.248-9.

ROCHA, M.G.B. Melhoramento de espécies arbóreas nativas. Belo Horizonte: Instituto Estadual de Florestas, 2002. 171p.

SANCHOTENE, M.C.C. Frutíferas nativas úteis à fauna na arborização urbana. Porto Alegre: FEPLAM, 1985. 71p. SILVA, I.C. Propagação vegetativa de Ocotea puberula Benth \& Hook e Ocotea pretiosa Nees pelo método de estaquia. 1984. 110p. Dissertação (Mestrado em Engenharia Florestal) - Setor de Ciências Agrárias, Universidade Federal do Paraná, Curitiba.

WEAVER, R.J. Reguladores del crecimiento en la agriculture. 2.ed. Barcelona: Trillas, 1982. 540p.

XAVIER, A.; SANTOS, G.A. Clonagem de espécies florestais nativas. In: ROCHA, M.G.B. (Ed.). Melhoramento de espécies arbóreas nativas. Belo Horizonte: Instituto Estadual de Florestas, 2002. 171p.

ZANETTE, F. Propagação da pereira Pirus comunis Var. Garber por estaquia lenhosa. 1995. 59p. Tese (Mestrado em Fitotecnia e Fitossanitarismo) - Setor de Ciências Agrárias, Universidade Federal do Paraná, Curitiba. 